Wels; ${ }^{6}$ Rheumazentrum Wien-Oberlaa, Vienna; ${ }^{7}$ Karl Landsteiner Institute of Clinical Rheumatology, Stockerau, Austria

Background: Remission or at last low disease activity is the aim of drug therapy in patients with chronic inflammatory rheumatic diseases. We evaluated disease activity in patients treated with biologics and using data of the Austrian biologic registry.

Objectives: The aim of this evaluation was to elucidate disease activity in patients with rheumatoid arthritis (RA), spondyloarthritis ( $\mathrm{SpA}$ ) and psoriatic arthritis (PsA) at baseline and at control-visits every six months after inclusion in BioReg.

Methods: Data were extracted from the Austrian BioReg registry (http://www. bioreg.at) which was initiated in 2009 to document patients treated with one of the biologics approved in Austria. Patients with ongoing biologic therapy as well as biologic-naïve patients starting biologic therapy can be included (baseline, $\mathrm{BL}$ ). Further documentation is recommended about every six months (V1,V2 up to V11). Meanwhile, 1877 patients (rheumatoid arthritis (RA) $n=1046$, ankylosing spondylitis ( $S p A) n=446$, psoriatic arthritis $(P s A) n=322$, other disease $n=63$ ) have been documented. Estimation of disease activity is done using DAS-28 as well as RADAI-5 in RA, SASPA in PsA, and BASDAI in SpA.

Results: DAS-28 (median values of $\mathrm{BL} ; \mathrm{V} 1 ; \mathrm{V} 2 ; \mathrm{V} 9 ; \mathrm{V} 10$ ) of patients with RA are 3,$30 ; 2,51 ; 2,58 ; 2,52 ; 2,49$, the respective RADAI-5 values are 3,$2 ; 2,4 ; 2,2$; $2.0 ; 2,3$. BASDAI in patients with SpA were 3,$60 ; 2,61 ; 2,45 ; 2,63 ; 2,20$. Median values of inflammation's laboratory markers (ESR in $\mathrm{mm} / 1$ st hour and CRP in $\mathrm{mg} / \mathrm{l})$ were always within the normal range (ESR and CRP in RA 15; 12; 12; 12,5; 14 and 2,$0 ; 2,0 ; 2,0 ; 2,0 ; 2,0 ;$ in SpA: $8 ; 6 ; 7 ; 8 ; 8 ;$ and 2,$0 ; 1,4 ; 1,4 ; 1,1 ; 1,0$ in PsA 9; 8; 9; 7 (V7); 6 (V8); and 1,6; 1,5; 1,4; 1,9 (V7); 0,8 (V8)).

Conclusions: Our data confirm the efficiency of therapy with biologicals. During 5 years of continuous treatment more than half of patients with RA reach and keep remission with a DAS-28 below 2,6 and normal values of ESR and CRP. Also patients with SpA and PsA show similar successful therapeutic response. Acknowledgements: BIOREG is supported by an unlimited industrial grant

Disclosure of Interest: None declared

DOI: 10.1136/annrheumdis-2017-eular.3898

\section{AB1145 GENDER, AGE AND PULMONARY FUNCTION IN DOMINICAN PATIENTS WITH RHEUMATIC DISEASES}

M.A. Santos $^{1}$, E. Tavera ${ }^{2}$, C. Tineo ${ }^{1}$, E. Loyo ${ }^{1}$, J. Reyes ${ }^{3} \cdot{ }^{1}$ Rheumatology, Hospital Regional Universitario Jose Maria Cabral y Baez; ${ }^{2}$ Pneumologyst, Union Medica Clinic: ${ }^{3}$ Investigation, Pontificia Universidad Catolica Madre y Maestra, Santiago, Dominican Republic

Background: Interstitial lung disease (ILD) is a frequent entity in patients with rheumatic diseases, worsening the prognosis of those who suffer it (1). Previous studies have used the GAP (Gender, Age, Pulmonary function) model stage system to determine mortality at 1,2 and 3 years (2). For stage I is $5.6 \%$ the first year, $10.9 \%$ second and $16.3 \%$ the third. GAP II has a mortality of $16.2 \%$, $29.9 \%$ y $42.1 \%$ for the first, second and third year. For stage III, 39.2\%, $62.1 \%$ and $76.8 \%$ respectively (3)

Objectives: To perform GAP model stage system in Dominican patients with Interstitial Lung Disease (ILD) related to Rheumatic Diseases (RD).

Methods: This is an observational, cross sectional study, with 42 patients who presented ILD related to RD. The GAP model stage system was determined by using demographic variables and pulmonary function tests such as spirometry and lung diffusion capacity (DLCO).

Results: 36 patients were female; the median age was $45 \pm 12$ years. The mean value for Forced Vital Capacity (FVC) was $72 \%$, Forced expiratory volume in 1 second (FEV1) 73\%, and the ratio FEV1/FVC 99\%. The DLCO mean value was $66 \pm 23 \mathrm{ml} / \mathrm{min} / \mathrm{mmHg}$. 35 patients $(83.3 \%)$ were in stage I, 7 patients $(16.6 \%)$ in stage II and none in stage III. The statistical significant variables were the time of diagnosis of the RD $(p=0.013)$; with 4.9 years for those in stage I and 10.8 years for stage II; the time of the diagnosis of the ILD $(p=0.003)$ with 2.1 years for patients in stage I and 4.8 years for stage II and smoking ( $p=0.063)$.

Conclusions: These findings suggest that the GAP model system is an useful tool to stage patients with interstitial lung disease related to rheumatic diseases. It can also help us make changes in treatment based on the stage. Special attention must be paid to those with a longer time of diagnosis of the RD, time of diagnosis of the ILD and/or smoking.

References:

[1] Vij R. Diagnosis and treatment of connective tissue disease-associated interstitial lung disease. CHEST 2013;143(3).

[2] Hoon S. Comparisons of prognosis between surgically and clinically diagnosed idiopathic pulmonary fibrosis using GAP model. Medicine Journal 2016; vol 95 (11).

[3] Ley B. A multidimensional index and staging system for idiopathic pulmonary fibrosis. Ann Intern Med. 2012, 156:684-691.

Disclosure of Interest: None declared

DOI: 10.1136/annrheumdis-2017-eular.2152

\section{AB1146 PHARMACOLOGICAL APPROACH OF KNEE OSTEOARTHRITIS TREATMENT IN PRIMARY CARE IN SPAIN}

M. Herrero Barbero ${ }^{1}$, S. Gimenez ${ }^{2}$, J. Vergara ${ }^{3}$, E. Viles I Lladó ${ }^{4}$, H. Martinez ${ }^{4}$, G. Rodríguez Roca ${ }^{5}$, L. Sánchez ${ }^{1}$, J.A. Díaz Muñoz ${ }^{6}$, J.F. Frias ${ }^{7}$, A. Castaño ${ }^{8}$, J.J. Jiménez Díaz ${ }^{9}$, Á. Rodríguez de Cossío ${ }^{10}$, R. Belenguer ${ }^{11}$, J.L. Llisterri ${ }^{12}$, J. Vergés Milano ${ }^{1,13}$ on behalf of EMARTRO. ${ }^{1}$ Bioiberica, Barcelona; ${ }^{2}$ Unidad de Gestión Clínica el Limonar, Malaga; ${ }^{3}$ Centro de Salud Huercal, Almería;

${ }^{4}$ Bioiberica S.A., Barcelona; ${ }^{5}$ Centro de Salud la Puebla de Montalbán, Toledo; ${ }^{6}$ Centro de Salud Ávila Rural, Ávila; ${ }^{7}$ Hospital Universitario Virgen de las Nieves, Granada; ${ }^{8}$ Centro de Salud Corella, Navarra; ${ }^{9}$ Centro de Salud Los Cubos, Burgos; ${ }^{10}$ Centro de Salud San Martin de la Vega, Madrid; ${ }^{11}$ Centro de Salud Algemesí; ${ }^{12}$ Centro de Salud Ingeniero Joaquín Belloch, Valencia;

${ }^{13}$ Osteoarthritis Fundation International, Barcelona, Spain

Background: Osteoarthritis $(\mathrm{OA})$ is the most prevalent joint disease and the leading cause of disability from 60 years onwards. In fact, $14,8 \%$ of the Spanish population has OA.

Objectives: This study aimed to analyze the indications and average doses prescribed in the treatment of knee osteoarthritis in Primary Care in Spain.

Methods: The EMARTRO study was designed as an observational, multicenter, transversal study to compare probability of suffering a comorbidities based on presence of symptomatic knee OA visited by GPs. Sociodemographic, anthropometric, clinical parameters and clinical variables of interest were recorded. The prescribed medications and doses indicated in syntomatic knee OA were analyzed in patients included in the EMARTRO study.

Results: A total of 1173 patients were included, of whom 646 had knee OA. Patients with OA had a mean (SD) BMI of 30.9 (5.1), systolic blood pressure 132.8 (14.5) and diastolic blood pressure $77.9(9.1) \mathrm{mm} \mathrm{Hg}$. They also had a mean of 4.3 (1.9) comorbidities, the most frequent were hypertension $358(62.2 \%)$, dyslipidemia 336 (58.3\%), diabetes mellitus II 126 (21.9\%), and gastroesophageal reflux $110(19.1 \%)$. As for the symptomatology, the patients presented a mean (SD) pain in Huskisson's VAS of 65.18 (15.27) $\mathrm{mm}$ and algofunctional Lequesne score of 11.35 (4.86).

Patients were treated with a mean of 2,2 medications. The $45.5 \%$ of osteoarthritic patients were treated as monotherapy, 35.5\% were taking 2 medications for osteoarthritis, $15.3 \% 3$ and $3.7 \% 4$ or more medications. It should be noted, taking into account the high levels of pain, that $15 \%$ of the patients did not receive any treatment.

Regarding prescribed medications for knee OA, 378 (58.2\%) patients were treated with paracetamol at a mean daily dose (SD) of $1,150.5(1,815.5) \mathrm{mg} ; 232(35.9 \%)$ received NSAIDs, with metamizole being the most prescribed at doses 1,092 (538) $\mathrm{mg}$, ibuprofen at doses $1,136(528,8) \mathrm{mg}$ and naproxen at doses 941,8 $(238,5) \mathrm{mg}$. Next, $131(20.3 \%)$ patients were treated with opioids, tramadol being the most frequent at doses 102.7 (49.7) $\mathrm{mg} ; 87$ (13.3\%) with SYSADOA being chondroitin sulphate the most frequent at doses 758.7 (247.7) mg. Finally, 87 $(13.3 \%)$ of the patients were treated with COX-2, mainly with etoricoxib at doses of 69.3 (27.1) $\mathrm{mg}$.

Conclusions: Although the patients presented many concomitant pathologies, it is frequent to approach osteoarthritis in polytherapy. In addition, despite the high symptomatology, patients are treated primarily with a mild analgesic such as paracetamol at doses lower than those recommended. It is paradoxical the high prescription of NSAIDs in a population with a high prevalence of cardiovascular and gastrointestinal pathologies as well as an increase in the prescription of opioids.

Disclosure of Interest: M. Herrero Barbero Employee of: Bioiberica, S. Gimenez: None declared, J. Vergara: None declared, E. Viles I Lladó Employee of: Bioiberica, H. Martinez Employee of: Bioiberica, G. Rodríguez Roca: None declared, L. Sánchez Employee of: Bioiberica, J. A. Díaz Muñoz: None declared, J. F. Frias: None declared, A. Castaño: None declared, J. J. Jiménez Díaz: None declared, Á. Rodríguez de Cossío: None declared, R. Belenguer: None declared, J. L. Llisterri: None declared, J. Vergés Milano Consultant for: Bioiberica, Employee of: Bioiberica

DOI: 10.1136/annrheumdis-2017-eular.3624

\section{AB1147 COMORBIDITY PROFILE IN MEN AND WOMEN AFFECTED BY SYNTOMATIC KNEE OSTEOARTHRITIS AND IMPACT OF GENDER IN THE SYMPTOMATOLOGY AND PERCEPTION OF HEALTH STATUS}

M. Herrero Barbero ${ }^{1}$, S. Gimenez ${ }^{2}$, J. Vergara ${ }^{3}$, E. Viles I Lladó ${ }^{4}, \mathrm{H}$. Martinez ${ }^{4}$ G. Rodríguez Roca ${ }^{5}$, L. Sánchez ${ }^{1}$, J.A. Díaz Muñoz ${ }^{6}$, J.F. Frias ${ }^{7}$, A. Castaño ${ }^{8}$, J.J. Jiménez Díaz ${ }^{9}$, Á. Rodríguez de Cossío ${ }^{10}$, R. Belenguer ${ }^{11}$, J. Vergés Milano ${ }^{1,12}$, J.L. Llisterri ${ }^{13}$ on behalf of EMARTRO. ${ }^{1}$ Bioiberica, Barcelona;

${ }^{2}$ Unidad de Gestión Clínica el Limonar, Malaga; ${ }^{3}$ Centro de Salud Huercal, Almería; ${ }^{4}$ Bioiberica S.A., Barcelona; ${ }^{5}$ Centro de Salud la Puebla de Montalbán, Toledo; ${ }^{6}$ Centro de Salud Ávila Rural, Ávila; ${ }^{7}$ Hospital Universitario Virgen de las Nieves, Granada; ${ }^{8}$ Centro de Salud Corella, Navarra; ${ }^{9}$ Centro de Salud Los Cubos, Burgos; ${ }^{10}$ Centro de Salud San Martin de la Vega, Madrid; ${ }^{11}$ Centro de Salud Algemesí, Valencia; ${ }^{12}$ Osteoarthritis Fundation International, Barcelona;

${ }^{13}$ Centro de Salud Ingeniero Joaquín Belloch, Valencia, Spain

Background: Osteoarthritis $(\mathrm{OA})$ is the most prevalent joint disease and the leading cause of disability from 60 years onwards. In fact, $14,8 \%$ of the Spanish 